(2) Open Access Full Text Article

REVIEW

\title{
Microbubble-mediated ultrasound therapy: a review of its potential in cancer treatment
}

This article was published in the following Dove Press journal:

Drug Design, Development and Therapy

2 May 2013

Number of times this article has been viewed

\author{
Stuart Ibsen' \\ Carolyn E Schutt ${ }^{2}$ \\ Sadik Esener ${ }^{3}$ \\ 'Moores Cancer Center, University \\ of California at San Diego, La Jolla, \\ CA, USA; ${ }^{2}$ Department \\ of Bioengineering, University \\ of California at San Diego, La Jolla, \\ CA, USA; ${ }^{3}$ Department \\ of Nanoengineering, Moores Cancer \\ Center, University of California at San \\ Diego, La Jolla, CA, USA
}

\begin{abstract}
The inherently toxic nature of chemotherapy drugs is essential for them to kill cancer cells but is also the source of the detrimental side effects experienced by patients. One strategy to reduce these side effects is to limit the healthy tissue exposure by encapsulating the drugs in a vehicle that demonstrates a very low leak rate in circulation while simultaneously having the potential for rapid release once inside the tumor. Designing a vehicle with these two opposing properties is the major challenge in the field of drug delivery. A triggering event is required to change the vehicle from its stable circulating state to its unstable release state. A unique mechanical actuation type trigger is possible by harnessing the size changes that occur when microbubbles interact with ultrasound. These mechanical actuations can burst liposomes and cell membranes alike allowing for rapid drug release and facilitating delivery into nearby cells. The tight focusing ability of the ultrasound to just a few cubic millimeters allows for precise control over the tissue location where the microbubbles destabilize the vehicles. This allows the ultrasound to highlight the tumor tissue and cause rapid drug release from any carrier present. Different vehicle designs have been demonstrated from carrying drug on just the surface of the microbubble itself to encapsulating the microbubble along with the drug within a liposome. In the future, nanoparticles may extend the circulation half-life of these ultrasound triggerable drug-delivery vehicles by acting as nucleation sites of ultrasound-induced mechanical actuation. In addition to the drug delivery capability, the microbubble size changes can also be used to create imaging contrast agents that could allow the internal chemical environment of a tumor to be studied to help improve the diagnosis and detection of cancer. The ability to attain truly tumor-specific release from circulating drug-delivery vehicles is an exciting future prospect to reduce chemotherapy side effects while increasing drug effectiveness.
\end{abstract}

Keywords: triggered drug delivery, ultrasound contrast agents, sonoporation

\section{Introduction}

The therapeutic role of cancer drugs is unique in the world of pharmacology in the sense that they are not designed to restore or replace the normal function of certain tissues, but rather they are meant to kill cells. The inherently toxic nature of these compounds makes their side effects on healthy tissue a major concern. ${ }^{1,2}$ When administered systemically, only a small fraction of the injected dose ever reaches the tumor, with the rest circulating through the healthy tissue of the body resulting in dose-limiting toxic side effects. ${ }^{3}$ Although tumors have been shown to have biochemical differences from healthy tissue, ${ }^{4}$ the degree of these differences ${ }^{5}$ and the ability of the tumors to develop drug resistance ${ }^{6}$ makes it difficult to develop a drug with true tumor specificity. For the foreseeable future, traditional chemotherapy drugs that attack rapidly dividing
Correspondence: Stuart Ibsen

Moores Cancer Center, University

of California at San Diego, 3855 Health

Sciences Dr \# 0815, La Jolla, CA

92093-08I5, USA

$\mathrm{Tel}+\mathrm{I} 8585349848$

Fax +l 8585349830

Email sibsen@ucsd.edu 
cells will be the most effective compounds at reducing and eliminating a wide range of tumor types. This also means that reducing the dose-limiting side effects of these compounds is an area of considerable interest.

The field of targeted drug delivery looks to address these side effects by encapsulating the drug within a vehicle that is injected systemically. One such vehicle approved by the US Food and Drug Administration (FDA) is Doxil ${ }^{\circledR}$, a liposomal formulation of doxorubicin. ${ }^{7,8}$ It has a long retention time of the $\mathrm{drug}^{9}$ and a long circulation time ${ }^{9-11}$ that helps protect healthy tissue, ${ }^{11}$ especially the very sensitive heart tissue. ${ }^{12-14}$ Doxil ${ }^{\circledR}$ relies on passive extravasation from the circulation into the tumor through its leaky vasculature. ${ }^{7}$ This allows the liposomes to pass through the heart with very little deposition. However, Doxil ${ }^{\circledR}$ will accumulate in other places in the body besides the tumor. The folds and creases in the hands and feet are one such place where Doxil ${ }^{\circledR}$ can extravasate and cause ulcers, making this a dose-limiting side effect. ${ }^{15}$ Because the doxorubicin is held in a crystalline form inside the liposome, it leaks out at a very slow rate which helps prevent heart exposure while in circulation. ${ }^{16}$ However, when extravasated into the tumor tissue, this slow leak rate also limits the maximum dose of doxorubicin that can accumulate in the tumor. ${ }^{17}$

A burst release of payload from the vehicle would be much more effective at creating a high drug concentration within the tumor, but this requires the drug-delivery vehicle to change its state from a relatively stable structure with a very slow leak rate to an unstable structure with a fast release. This requires the presence of a trigger, specific to the tumor, which can achieve a state change in the vehicle. One class of possible triggers that has received a considerable amount of attention is the inherent biochemical and environmental differences between the tumor and the healthy tissue., ${ }^{4,18}, 19$ Enzymes overexpressed by the tumor are a common example. ${ }^{20-22}$ The liposomal outer membranes of the vehicles can be designed with special enzymatically cleavable bonds that are susceptible to degradation by these overexpressed enzymes. Once in the tumor, these enzymes degrade the liposome membrane, resulting in a rapid disintegration. The main challenge in achieving true tumor specificity with enzyme-based approaches has been the natural enzymatic activity of the liver. ${ }^{23}$ The liver has most of the same types of enzymatic activity as the tumor, but on a much larger scale, resulting in massive drug release into the liver. ${ }^{23}$ Other healthy tissue can also display similar biochemical properties to the tumor, reducing the tumor specificity of the approach. ${ }^{24}$
Tumor-targeting ligands have been used in an effort to try to increase the amount of vehicle that accumulates in the tumor above the level of passive extravasation. ${ }^{25,26}$ The surfaces of the vehicles can be functionalized with tumorspecific targeting peptides or antibodies ${ }^{27}$ to attach to surface markers that are known to be overexpressed on the surface of certain tumor cells. ${ }^{24}$ However, these tumor receptors are rarely unique to the tumor, ${ }^{5}$ causing vehicles to accumulate in other healthy tissues, especially in the liver and spleen, causing local toxicity. ${ }^{28}$ For a surface marker to be considered truly tumor specific, it must be overexpressed at a level of at least 100 times above the healthy tissue, ${ }^{5}$ which limits the effectiveness of this targeting to just those patients whose tumors have this special property. For those select patients, it has been found that eliminating the tumor cells that have this high degree of overexpression selects for tumor cells that have a lower degree of expression shifting the tumor cell population to a more resistant type. ${ }^{6}$ An added degree of complication for the drug design is that once the vehicles attach to the markers they are often endocytosed, requiring subsequent endosomal escape of the drug. ${ }^{6,29,30}$

The neovasculature that develops to feed these tumors has special surface markers that have made it a target for therapeutic intervention. ${ }^{31,32}$ The idea is to starve the tumor of oxygen and nutrients to slow its growth by killing the neovasculature. The neovasculature has a higher degree of genetic stability than the tumor and its unique marker expression is not subject to change like that in the tumor. However, neovasculature is fairly common in the body, including the stomach and intestines. ${ }^{33,34}$ When the neovasculature is destroyed in these organs, it creates a whole set of dose-limiting side effects.

These biochemical triggers or markers often do not provide sufficient contrast between the tumor and the healthy tissue to be truly tumor specific. ${ }^{35}$ The use of biochemical triggers is further complicated by the high degree of variability that exists in tumors from patient to patient, ${ }^{6,36}$ which requires each patient's tumor to be analyzed through a difficult and lengthy process. The inherently subtle differences between the tumor and the healthy tissue make the use of biochemical triggers a challenging approach to achieve true tumor specificity.

\section{Desired properties of drug- delivery vehicles}

Based on the experience of the existing drug-delivery vehicle technologies, two main groups of desirable vehicle traits can be identified. 
The first set of properties comprises the opposing drugcontainment requirements. The vehicle must be able to contain the drug without significant loss as it circulates to protect the healthy tissue it passes through. The vehicle must also be able to rapidly release its payload once it reaches the tumor tissue. A triggering mechanism to initiate this state change that is independent of biochemistry would help make the release a truly tumor-specific event. Ultrasound lends itself well to being such a trigger. By focusing the ultrasound from outside the body, significant amounts of energy can be deposited safely and noninvasively into small volumes of tissue deep inside the body. The focus of ultrasound is described as the $-6 \mathrm{~dB}$ focal zone, and at $1 \mathrm{MHz}$ it can be on the order of a few cubic millimeters in volume, ${ }^{37}$ allowing the ultrasound to effectively highlight just the tumor tissue, creating a stark differentiation between it and the healthy tissue. Because the intensity of ultrasound is highest in the focal region, vehicles outside the focal zone would not be triggered $^{38}$ as shown schematically in Figure 1.

The activation of microbubble-based drug-delivery vehicles only inside the focal region of ultrasound was demonstrated in an agar tissue phantom by Ibsen et $\mathrm{al}^{38}$ and is reproduced in Figure 2. A channel was molded through a block of agar and coated with avidin to simulate a blood vessel with targeting ligands in tissue. Fluorescently labeled drug-delivery vehicles that contained a microbubble were designed with biotinylated lipids on the inside. Upon focused ultrasound activation, the vehicles fragmented only in the focal zone revealing the biotin. These fluorescent biotinylated fragments then bound to the avidin on the channel surface, marking the location of activation. The drug-delivery vehicles were present in the entire length of the channel at the time of ultrasound exposure, but only those in the focal zone were activated and were left bound after washing the channel with water.

The second set of vehicle requirements deal with circulation time and cell penetration. The circulation time of the vehicles needs to be as long as possible to get the maximum number of vehicles passing through the tumor. However, the properties that allow these vehicles to have long circulation times are often not the properties that will allow efficient passage of payload through cell membranes once it reaches the tumor. The triggering event that releases payload can also help with this requirement if the vehicle has a multilayer design. The outer layers of the vehicle can convey long circulation properties, and the inner payloads can have efficient cellular penetration. The triggering event that releases payload can also effectively remove this outer circulation layer once the vehicle reaches the desired location.

\section{Ultrasound-responsive trigger}

Ultrasound can cause local heating of tissue in the focal zone when used at high intensity levels. The field of high intensity focused ultrasound looks to use the heat itself as an anticancer treatment for tumors that are not located near critical healthy tissue. ${ }^{39,40}$ Designs of temperature-sensitive liposome-based vehicles look to use that heat to destabilize the lipid shell and release payload. ${ }^{41}$ However, the heat deposited in the tissue dissipates from the focal zone by blood flow convection and by conduction. ${ }^{42-44}$ As the temperature rises, the tissues are stimulated to vasodilate, causing increased blood flow through the tissue. ${ }^{43}$ This heat dissipation makes it difficult to achieve sufficient heating in the tissue for sufficient periods of time to cause tissue death or to melt the liposomes and achieve release, especially in the well vascularized tumor periphery. ${ }^{44}$ If sufficient heating is achieved in the focal zone, the increased blood flow will widen the tissue death and liposome activation areas to downstream tissues and the payload that is released will also spend less time in the desired tissue. One way to counter the heat dissipation is to use higher intensities of ultrasound. This, however, can lead to the formation of bubbles in and around the focal zone which quickly distort the energy profile of the ultrasound beam, leading to unpredictable regions of tissue damage..$^{45,46}$

Low intensity ultrasound, like that used for imaging, has little effect on tissue temperature or structure. This makes it safe to use on tumors that are near sensitive anatomy. The use of low intensity ultrasound itself has been shown to increase drug delivery to ensonified tissues, ${ }^{47,48}$ presumably by increasing cell permeability. However, these low intensities fail to cause a burst release of drug from the vehicles because the vehicles have the same density as the surrounding water. The only way to get the low intensity ultrasound to trigger a state change in a vehicle is if the density between the vehicle and surrounding water is significantly different. The highest density differences are between liquid and gas, and the best gas-filled particle small enough to pass through circulation is a microbubble. ${ }^{49}$

\section{Microbubble/ultrasound interactions}

Microbubble technology was initially developed and FDA approved for use as ultrasound contrast agents. ${ }^{50,51}$ These 1-2 $\mu \mathrm{m}$ diameter microbubbles are filled with a perfluorocarbon (PFC) gas and air mixture, which is critical in preventing osmotically driven size changes of the microbubbles under physiological conditions. Microbubbles made with pure air would quickly dissolve away and collapse. Microbubbles made with a concentration of PFC gas that is too high would allow the PFC to condense into a liquid droplet, resulting in 


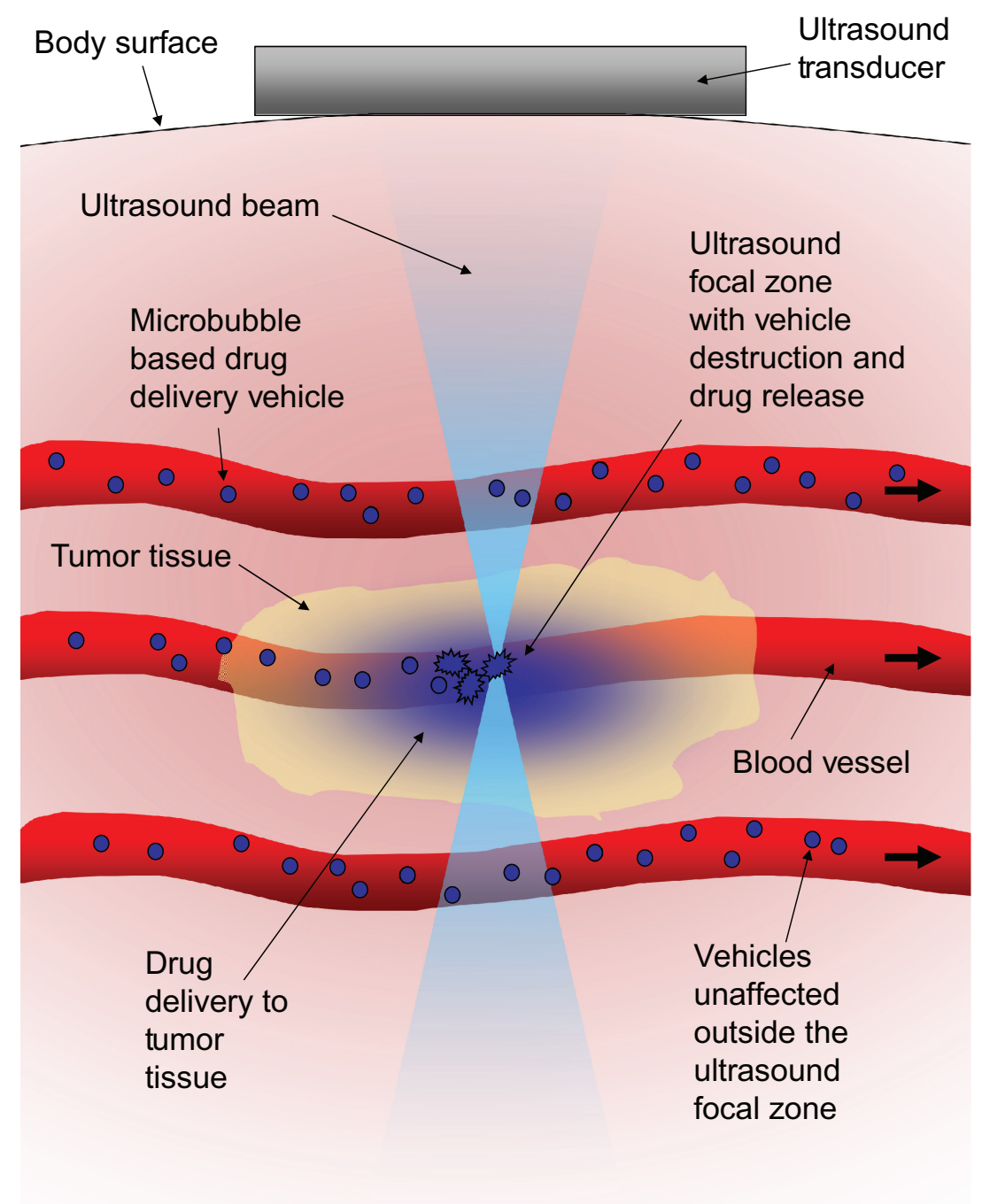

Figure I Schematic representation of the concept behind ultrasound-triggered drug delivery.

Notes: The ultrasound can be focused to small volumes of tissue deep within the body. Ultrasound triggerable vehicles can pass through the diffuse portions of the ultrasound beam without any effects. Vehicles that pass through the ultrasound focal volume experience a significantly higher intensity than in the other diffuse portions of the beam, resulting in vehicle activation. The focal zone location is under the control of the physician and can be directed specifically at the tumor region.

microbubble collapse. Microbubbles made with too much air relative to the PFC gas would create an osmotic driving force facilitating the nitrogen to leave the microbubbles, resulting in their shrinkage to the collapse radius. ${ }^{52,53}$ The correct ratio allows the PFC gas to keep the microbubble inflated, while the nitrogen creates a stable dynamic equilibrium between the gas dissolved in the blood and the gas inside the microbubble. An example of a common PFC gas used in microbubbles is perfluorohexane which has maximum in-vivo stability at $2.2 \mathrm{mg} / \mathrm{mL}$ of air. $^{52}$

The water molecules at the microbubble gas-water interface hydrogen bond with one another horizontally in line with the interface. This creates a constricting force over the entire surface of the microbubble, resulting in a net surface tension force that points inward and increases the pressure on the gas within the microbubble. ${ }^{54}$ This surface tension pressure increases the rate at which the gas will dissolve. The surface tension can be significantly reduced and even reach $\sim 0 \mathrm{mN} / \mathrm{m}$ by creating a lipid monolayer over the surface of the microbubble. ${ }^{55,56}$ The hydrophobic tails of the lipids associate with the gas phase, and the hydrophilic head groups interact with the water molecules. This interaction prevents the formation of ordered hydrogen bonding around the microbubble. Figure 3 shows a typical population of microbubbles just after manufacturing from Benchimol et al. ${ }^{57}$ Figure $3 \mathrm{~A}$ shows the microbubbles under white-light illumination. The index of refraction difference between the water and the gas causes the microbubbles to act like individual optical lenses, creating ring-like distortions around the microbubble and causing their centers to show up as dark circles. Figure 3B shows the same field of view under fluorescent microscopy, where a lipophilic red fluorescent dye 


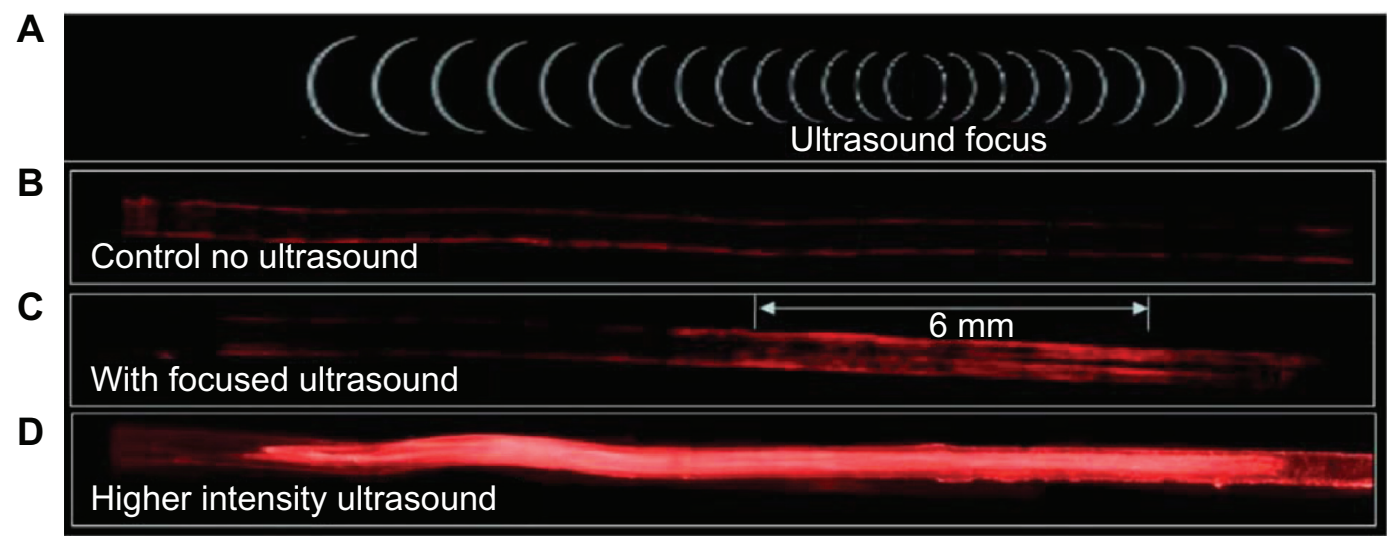

Figure 2 In-vitro demonstration of the localized activation of microbubble-based drug delivery vehicles. An agar tissue phantom with a molded channel down the center was used to model a blood vessel. Avidin was coated on the surface of the entire channel to simulate a targeting molecule. Fluorescently labeled drug-delivery vehicles containing a microbubble were introduced into the entire length of the channel. The inside of the vehicles were biotinylated to cause binding to the avidin-coated channels when exposed by ultrasound-induced vehicle rupture. (A) The focal zone of the ultrasound beam. (B) The fluorescent vehicles were introduced to the channel then washed out with water with no ultrasound exposure to demonstrate the background level of nonspecific binding. (C) When low intensity ultrasound was applied, only the vehicles in the focal zone were fragmented revealing the biotin which allowed binding to occur to the avidin-coated channel walls. This marked the location of activation. Vehicles were distributed throughout the channel, but only those that were activated were left behind after washing. (D) Higher intensity ultrasound caused a larger number of vehicle activations and expanded the effective focal zone over which activation would occur.

Reprinted from Ibsen S, Benchimol M, Simberg D, Schutt C, Steiner J, Esener S. A novel nested liposome drug delivery vehicle capable of ultrasound triggered release of its payload. J Control Release. 20II;155(3):358-366, Copyright 20II, with permission from Elsevier. ${ }^{38}$

has been used to highlight the lipid monolayer surrounding the surface of the microbubble. Surface coatings of albumin have a similar effect of reducing the surface tension around the microbubble. ${ }^{54}$ Over time, the PFC gas in these stabilized microbubbles will dissolve into the blood and be eliminated through exhalation.

The density difference between the PFC gas and the water allows the microbubble to shrink to half its original diameter and expand to four times its original diameter with the compression and rarefaction portions of the ultrasound pulse. ${ }^{58-61}$ The driving ultrasound frequencies are in the megahertz range, requiring specially designed instrumentation with extremely high frame rates of up to 6.2 mega frames per second to document ultrasounddriven oscillation of single microbubbles. ${ }^{59,62}$ Streak camera images and individual still frames of this interaction have been captured by Bloch et al and have been reproduced in Figure $4 .^{58}$ The streak camera image in Figure 4E shows the upper and lower boundary of the microbubble over time, documenting the condensing and expanding phases of microbubble ultrasound interaction. The still frame in Figure 4A shows the whole microbubble before ultrasound exposure, and Figure 4B shows it during the expansion. The microbubble is destroyed after two full oscillations at $41.5 \mu \mathrm{s}$ on the streak camera image. Figure 4C shows the remnant gas fragments, and Figure 4D shows that the gas had all dissolved.

Microbubble interaction with ultrasound can result in a rich diversity of responses beyond oscillation, as shown schematically in Figure 5. These responses include lateral translations of the microbubbles, ${ }^{63}$ escape and dissolution of gas from microbubbles, ${ }^{64}$ and diameter changes of freefloating microbubbles ${ }^{65,66}$ (Figure 5A). Changes to the internal structure of the microbubble during oscillation against a solid surface ${ }^{67}$ are particularly interesting, as they model what might be happening to microbubbles near the vascular walls. These oscillations can result in microstreaming of the fluid around the microbubble edges ${ }^{68}$ which creates a shear force over the surface of nearby cells and can disrupt cell and liposome membranes ${ }^{68,69}$ (Figure 5B). These microstreaming flow fields have been documented by Collis et $\mathrm{al}^{70}$ and are reproduced in Figure 6. At the correct frequency, shell stiffness, and microbubble size, a resonant interaction with the ultrasound can occur where the microbubble undergoes

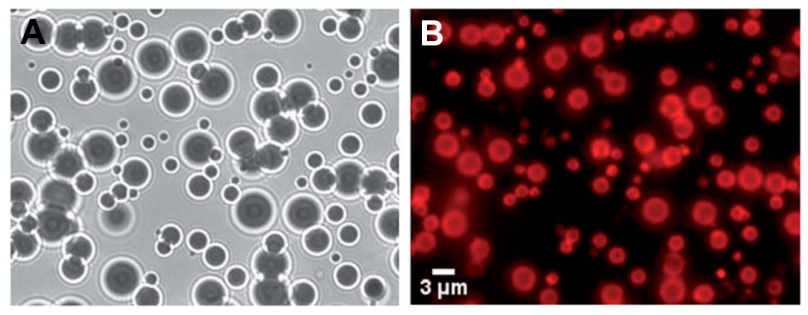

Figure 3 Images of microbubbles taken just after manufacturing. (A) White light illumination of the microbubbles. The density difference between the gas inside the microbubble and the surrounding water caused them to behave like lenses making them appear as dark circles with ring structures around them. (B) Fluorescent image of the same field of microbubbles showing the fluorescent dye that had been incorporated into the stabilizing lipid monolayer surrounding each microbubble. Notes: These fluorescent images were not subject to the same distortions seen in the white-light images and show the actual physical dimensions of the microbubbles. Reproduced by permission of The Royal Society of Chemistry. Benchimol MJ, Hsu MJ, Schutt CE, Hall DJ, Mattreyc RF, Esener SC. Phospholipid/carbocyanine dye-shelled microbubbles as ultrasound-modulated fluorescent contrast agents. Soft Matter. Epub January 4, 2013.57 


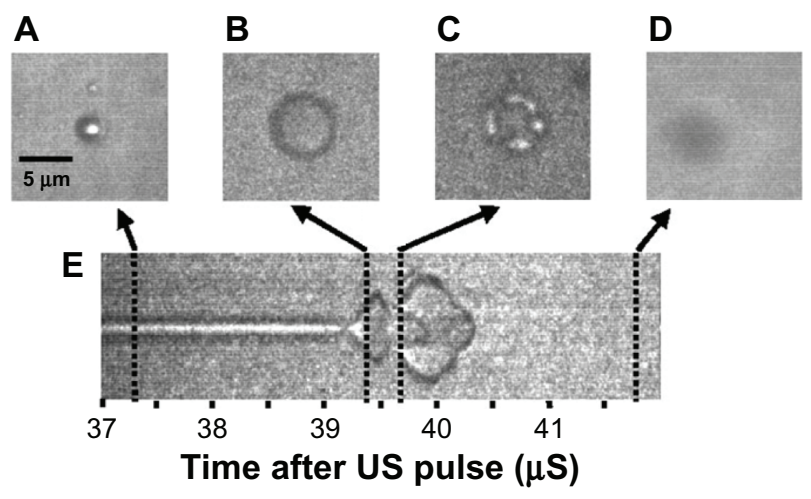

Figure 4 Streak camera images of a microbubble undergoing size oscillations when exposed to ultrasound. (A) The original resting size of the microbubble. (B) As the ultrasound pulse hit the microbubble the rarefaction portion caused the microbubble to expand. (C) The microbubble was destroyed, and remnant gas fragments were left behind. (D) All the remnant gas dissolved into the water. (E) A streak camera image showing only the width of the microbubble as a function of time, documenting how the diameter changed over the course of the ultrasound exposure.

Note: The ultrasound pulse actually hit the microbubble just after $39 \mu \mathrm{s}$.

Reprinted with permission from Bloch SH, Wan M, Dayton PA, Ferrara KW. Optical observation of lipid-and polymer-shelled ultrasound microbubble contrast agents. Appl Phys Lett. 2004;84(4):631-633. Copyright 2004, American Institute of Physics. ${ }^{58}$

such large size variations that it violently implodes in an event known as inertial cavitation, which can send out a radial shockwave ${ }^{71}$ (Figure $5 \mathrm{C}$ ). A directed jet is also possible, resulting from asymmetric microbubble collapse. ${ }^{72}$ Actual high speed video of the asymmetric collapse of a microbubble was collected by Postema et al, and still images are reproduced in Figure $7 .{ }^{61}$ The microbubble shown in Figure 7A underwent an asymmetric collapse upon ultrasound exposure, where the left side involuted, creating a jet which penetrated through the right side of the microbubble as shown in Figure 7B. As the microbubble completely collapsed, a jet of fluid was created in the direction of the involution. The debris field resulting from such a jet is shown in Figure 10A.

The cellular effects of these inertial cavitation shockwaves and other vibrational modes of ultrasound interaction with cells have been documented by imaging a cell population before and after insonation. ${ }^{72-74}$ The use of electron microscopy and flow cytometry ${ }^{75}$ as well as atomic force microscopy ${ }^{76,77}$ have given details about an effect know as sonoporation. During sonoporation, the shockwaves physically create small transient ruptures in cell membranes ${ }^{78,79}$ on the order of $100 \mathrm{~nm}$ in diameter. They remain effectively open for up to 20 seconds, ${ }^{80,81}$ allowing molecules and even DNA fragments to flow down their concentration gradient into the cell. ${ }^{80,82}$ Microbubble cavitation events have also been shown to cause rupture to capillary walls, allowing particles to extravasate into the surrounding tissue. ${ }^{83}$ Figure 8 shows schematically how these shockwaves can facilitate drug delivery to the tumor region.

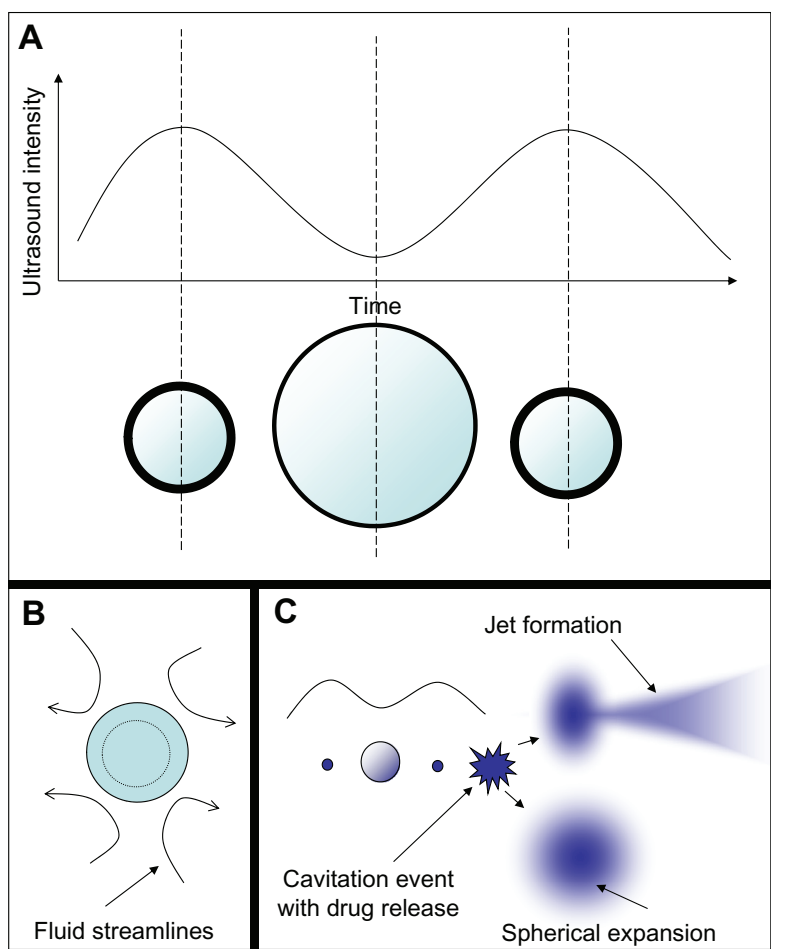

Figure 5 Microbubble interactions with ultrasound. (A) The microbubble diameter changes when exposed to the pressure waves of ultrasound. During the compression portion of the wave the microbubble diameter shrinks, while during rarefaction the microbubble expands. The diameter can change by a factor of eight between these two states. (B) Pressure differences are created around the microbubble as it undergoes vibrational size changes, driving the surrounding fluid to flow around it in various patterns. This microstreaming can be used to disrupt nearby membranes. (C) When resonance is achieved between the microbubble oscillations and the driving ultrasound frequency, the microbubble can undergo an adiabatic implosion. Notes: This sends out a shockwave that can fragment nearby lipid membranes. The two main debris field patterns that have been observed are spherical expansion and jet formation. The jets are formed by asymmetric collapse of the microbubble during inertial cavitation.

These oscillations and inertial cavitation events are unique from a mechanistic trigger standpoint. Harnessing both the volume changes and the sonoporation shockwave production from the microbubble interaction with ultrasound is the key to making the microbubble a tumor-specific trigger and facilitating payload delivery into cells.

\section{Microbubble-based drug-delivery vehicle designs}

Microbubbles have been used in several different drugdelivery vehicle designs, as shown in Figure 9. The basic microbubble structure is shown in Figure 9A. Charged payloads, such as certain drugs or therapeutic DNA designed to induce apoptosis in cancer cells, can be adhered to the surface of microbubbles using electrostatic attraction ${ }^{84}$ (Figure 9B). The adhered DNA has been shown to have enhanced resistance from nucleases present in blood that would normally destroy free DNA strands. ${ }^{84}$ The DNA 
A

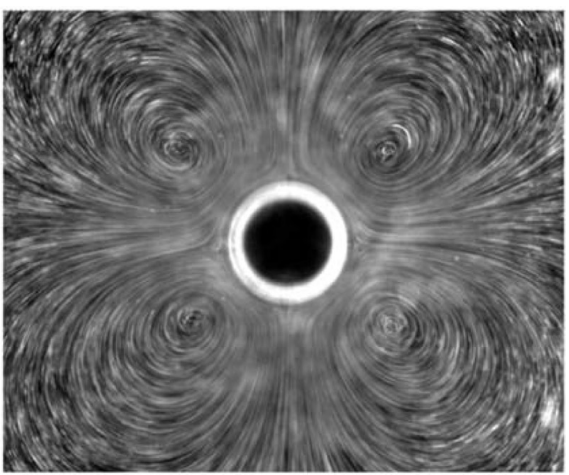

B

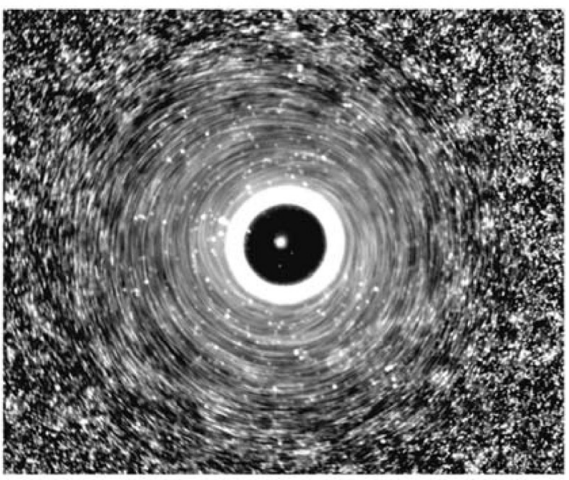

C

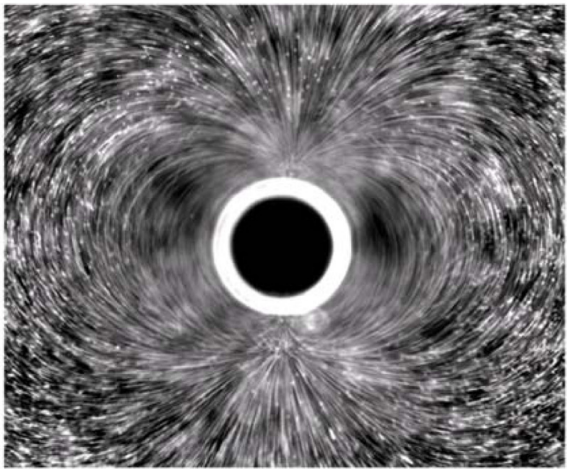

Figure 6 Different microstreaming fluid flow patterns around microbubbles oscillating in diameter under the influence of ultrasound. The microbubbles are the dark circles with white outlines in the center of each frame. The little white dots are particles that mark the streamlines of fluid flow patterns in the surrounding water. The microbubbles are all roughly the same size in each frame, and the different flow patterns shown in frames $(\mathbf{A}-\mathbf{C})$ arise from different driving ultrasound frequencies. Reprinted from Collis J, Manasseh R, Liovic P, et al. Cavitation microstreaming and stress fields created by microbubbles. Ultrasonics. 2010;50(2):273-279. Copyright 2010, with permission from Elsevier. ${ }^{70}$

can be shaken off the surface of the microbubble when exposed to ultrasound. Its delivery into the target cells can be enhanced by the sonoporation effect, ${ }^{78}$ which is significant because DNA is rarely taken up by mammalian cells in its pure form due to the large size of the DNA and the various membranes and barriers of the cell. ${ }^{85}$ Microbubble delivery of DNA does not require the extra DNA used by viral vectors, which avoids concerns about the possible side effects of the extra viral DNA. ${ }^{79}$ Microbubbles can be used on a broader range of cell types, since viral vectors are only effective on certain cells which are capable of being infected. ${ }^{86}$ The
A

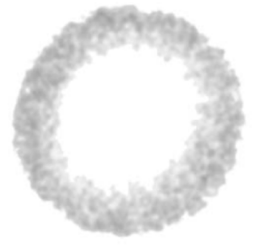

C

E

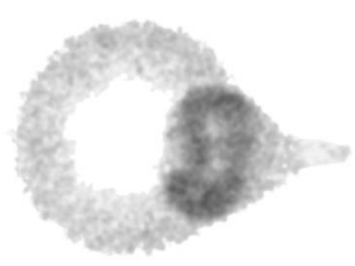

B
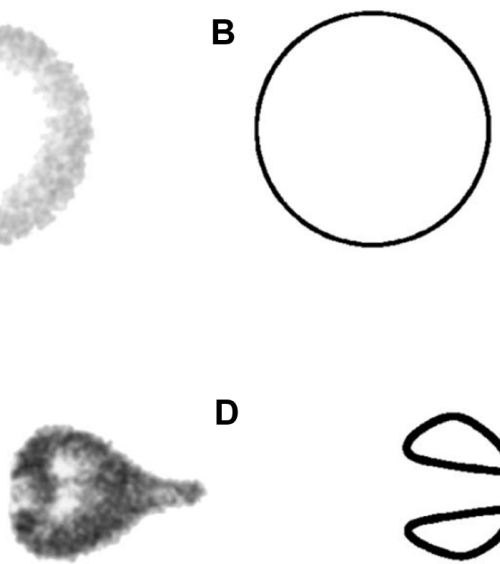

$\mathbf{F}$

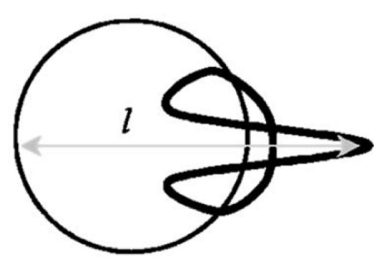

Figure 7 Still images from a high speed video of a microbubble undergoing asymmetric collapse during inertial cavitation creating a fluid jet. (A) The original microbubble before ultrasound exposure. (B) A schematic of the microbubble outline before ultrasound exposure. (C) The microbubble during ultrasound exposure, undergoing an asymmetric collapse where the left side actually collapsed through the airspace of the microbubble and penetrated through the right side. (D) Schematic showing the microbubble outline during collapse. (E) Overlaid images of the microbubble before ultrasound exposure and during collapse. (F) Schematic of the before and during ultrasound exposure outlines of the microbubble.

Reproduced from Postema et al..$^{61}$

focusing capability of the ultrasound makes microbubble delivery more spatially localized than the use of cationic liposomes, which are injected systemically and fuse with cell membranes in an indiscriminate manner. ${ }^{85}$ The use of lasers in optoporation ${ }^{87}$ and intense electric fields used in electroporation ${ }^{88}$ can increase delivery efficiency with isolated cell populations in vitro but are not suited for use in vivo. ${ }^{89}$

The protective lipid monolayer that covers the microbubble can be used to carry hydrophobic drugs that naturally partition into it ${ }^{90}$ (Figure 9C). To increase loading capacity beyond the microbubble's limited surface area, the protective lipid monolayer can be thickened with extra oil to carry additional hydrophobic drugs ${ }^{91,92}$ (Figure 9D). The microbubble destruction upon ultrasound exposure fragments the oil and lipid shell, creating small particles that carry the drugs inside them.

The internal volume of drug-loaded liposomes can be used to achieve even greater drug loading than what the surface area or shell volume of the microbubble can provide. For 


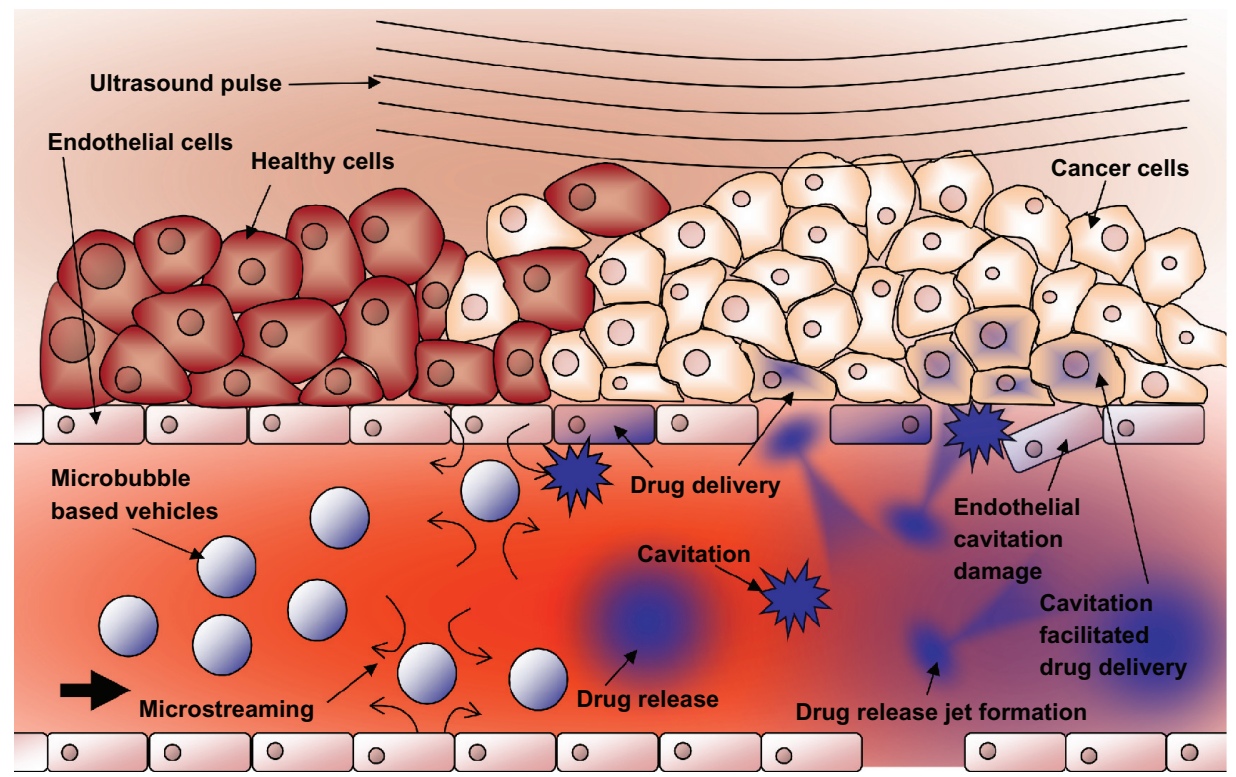

Figure 8 Schematic representation of ultrasound-triggered drug delivery on the cellular level.

Notes: Microbubble-based drug-delivery vehicles flow through the vasculature into the ultrasound focal zone within the tumor region where they undergo cavitation. Microbubbles on the edge of the focal zone undergo some vibration, resulting in microstreaming. These two mechanisms help to increase the permeability of the cell membranes of the nearby endothelial cells, facilitating drug delivery to the tumor neovasculature. The inherent leakiness of the tumor vasculature allows some of the released drug to gain access to the tumor cells, which can be enhanced though damage done to the vasculature by the inertial cavitation shockwave. The concentration of the drug in the tumor circulation increases with further ultrasound pulses that allow fresh vehicles to enter the tumor. Over time, the drug has a chance to spread further into the tumor tissue. Drug that is not taken up by the tumor is swept downstream where it is diluted into systemic circulation, creating a dramatically smaller systemic dose than would be encountered by simply injecting the free drug into circulation.

the mechanical actuation of the microbubble to be useful in destabilizing liposome structures, both the microbubble and the liposome have to be within $40 \mu \mathrm{m}$ of one another. Simply injecting both free microbubbles and drug-loaded liposomes separately from one another into circulation, both fitted with the same tumor-targeting ligands so both accumulate within the tumor tissue, would require them to accumulate at very high densities to get the close proximity needed to achieve significant release.

To address this proximity issue, one design attached small drug-loaded liposomes to the surface of the microbubbles to ensure that the mechanical triggering of the microbubble would effectively disrupt the liposomes and rapidly release the drug ${ }^{93}$ (Figure 9E).

There has been interest in encapsulating the microbubbles inside drug-loaded liposomes ${ }^{38,94-98}$ to both protect the microbubble and to ensure the microbubble actuation releases the entire payload. Recently, these structures have been successfully manufactured using a modified detergent dialysis method $^{38}$ (Figure 9F). This nested structure presents a smooth outer surface which increases stability of the particle and reduces immune recognition. Each vehicle has an internal microbubble trigger, ensuring the outer liposome will be disrupted. Upon exposure to ultrasound, the entire structure fragments, creating a burst release of the entire payload with forceful jet-like patterns. These activation events have been documented by Ibsen et $\mathrm{al}^{38}$ and are reproduced here in Figure 10. Some of the payload may be swept into systemic circulation instead of penetrating into the tumor cells; however, it will be diluted significantly reducing its overall systemic concentration.

\section{Microbubbles for use in imaging and diagnostics}

The ability of the microbubbles to undergo size changes when ensonified with ultrasound also allows them to be used for tumor imaging and diagnostics separately or in combination with their drug-delivery capability.

When injected into systemic circulation, the populations of microbubbles are highly reflective to ultrasound waves, allowing the vasculature they flow through to light up with high contrast on ultrasound imaging systems compared with the rest of the fluid-filled tissue..$^{99,100}$ This allows abnormalities in circulation and in the heart to be imaged where the microbubbles are seen to be absent from tissue regions suffering from circulation blockages. ${ }^{100}$ Individual microbubbles can be imaged using nonlinear resonance behavior techniques, including second harmonic imaging. ${ }^{101}$ As shown in Figure 9A, microbubbles can be conjugated to targeting ligands specific to markers expressed on the 


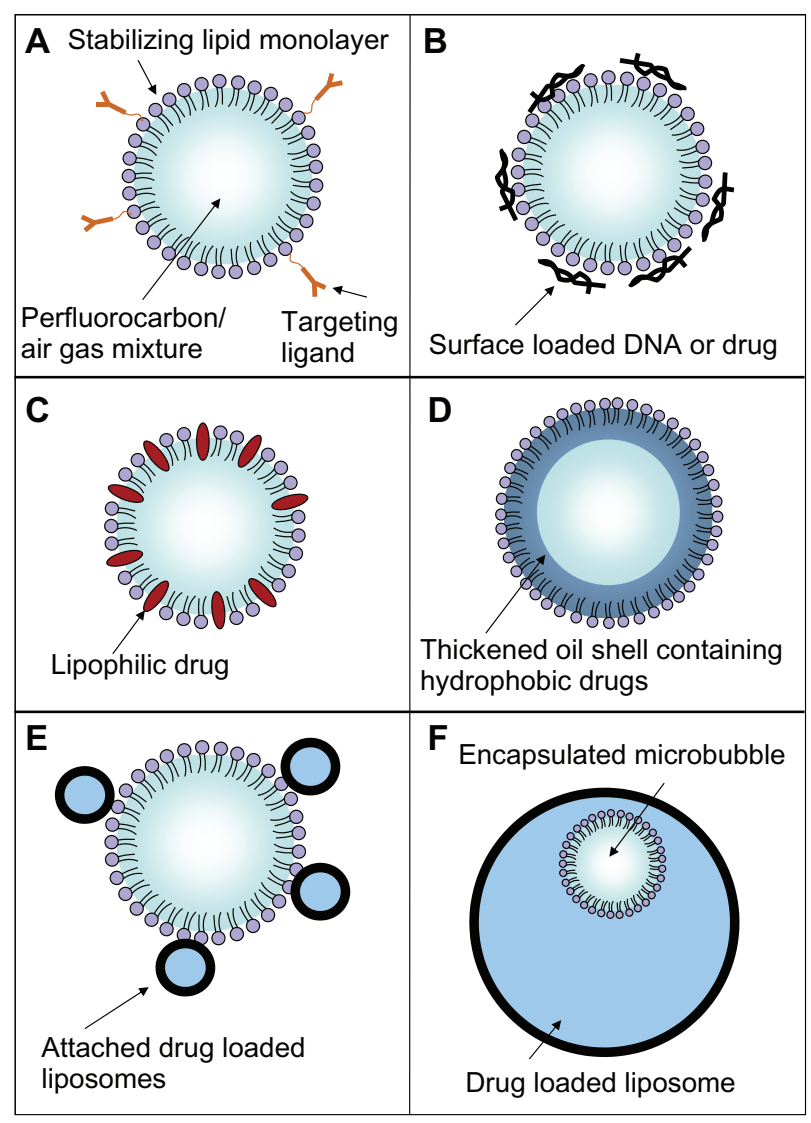

Figure 9 Schematic representations of various drug-delivery vehicle designs. (A) The basic microbubble design with a lipid monolayer stabilizing the PFC/air gas core. Targeting ligands can be conjugated to the surface to help facilitate accumulation of the microbubble in desired tissues. These ligands can be antibodies or short peptide sequences such as cyclic RGD. (B) The microbubble itself can be a vehicle by attaching drugs and even DNA to the surface through the use of electrostatic attractions. (C) Lipophilic drugs can be incorporated into the lipid monolayer shell of the microbubble. (D) The stabilizing shell can be thickened with an oil layer, allowing hydrophobic drugs to be carried within it. (E) Drug-filled liposomes can be attached to the surface of the microbubble. When the microbubble is exposed to ultrasound, the liposomes are disrupted by the mechanical actuation releasing drug. (F) The microbubble can be encapsulated within a liposome along with the drug. When exposed to ultrasound, the microbubble ruptures the outer liposome, releasing the payload.

surface of tumor cells ${ }^{102}$ or to ligands specific for integrins of neovasculature feeding the tumor. ${ }^{103-105}$ These targeted microbubbles can accumulate in the tumor tissue where they will stay for a period of time associated with the molecules on the surface of the cells. ${ }^{106}$ The microbubbles that do not attach to the target tissue will eventually clear from circulation, leaving only the targeted ones behind, leading to the concept of ultrasound-based molecular imaging. ${ }^{106}$ Scanning with ultrasound imaging systems can quickly find these remaining clusters of microbubbles attached to surface markers, revealing the location and size of potential tumor sites. The use of these biochemical targeting mechanisms will also result in the microbubbles accumulating in healthy tissue that has similar properties to the tumor; however, the main differences between these imaging microbubbles and drug-delivery vehicles is that the imaging microbubbles will eventually dissolve with no lasting effect on the healthy tissue, whereas the drug-delivery vehicles will leak their payloads and cause side effects in the healthy tissue over time. The microbubble accumulation in healthy tissue could yield falsepositive areas if doing an entire body scan to find possible tumors. However, in cases where the location of a potential tumor is known, such as in the prostate or in the breast, the specific location can be scanned for a significant microbubble accumulation to help identify a lesion. Fluorescent dyes can be incorporated into the surface of the microbubble to allow for their location to be determined using both ultrasound and fluorescent imaging. ${ }^{107}$

Using these ultrasound techniques along with traditional $\mathrm{X}$-ray mammography for breast cancer screening purposes is important to catch tumors early in their development, leading to increased long-term survival of patients. Using X-ray mammography alone allows physicians to know the location of possible tumor lesions, but $76 \%$ of the positive results are ultimately found to be false positives. ${ }^{108}$ Reducing this false-positive rate requires additional knowledge about the biochemistry of the observed mass and looking for strong indicators of tumor-associated conditions and the hallmarks of malignancy including hypoxia and angiogenesis. It is well known that malignant breast tissue displays a significant decrease in tissue oxygenation from healthy tissue. ${ }^{109,110}$ These regions of hypoxic tissue have been shown to be heterogeneously distributed throughout the tumor volume. ${ }^{35}$ These regions can occur early in the development of the tumor and are especially prevalent at larger tumor sizes. ${ }^{35}$ Hypoxia has also been associated with more aggressive forms of the disease that result in worse clinical outcome. ${ }^{11}$ The hypoxic tissue can be detected using optical spectroscopic imaging techniques that measure the absorption of oxygenated and deoxygenated hemoglobin which can be used to determine tissue oxygenation and total hemoglobin content in tissues. ${ }^{12,113}$ The use of these optical techniques in deeper tissue inside the body has been significantly hindered by the highly scattering properties inherent to the tissue itself. The light path of a single photon in tissue is scattered to such a high degree that it is very difficult to tell whether that photon originated from the tumor.

To address the difficulty in locating the origin of this light, microbubble-based optical imaging contrast agents are being developed that take advantage of the size changes the microbubble can undergo when exposed to ultrasound. ${ }^{114}$ Concentration-dependent dye quenching is a well known phenomenon, ${ }^{109-111}$ and a lipophilic concentration-dependent 


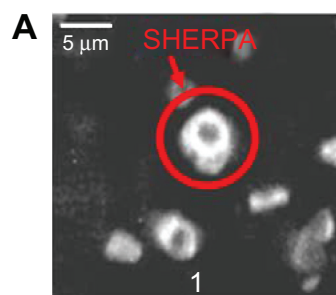

Before ultrasound

B

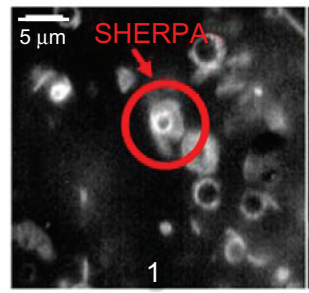

Before ultrasound

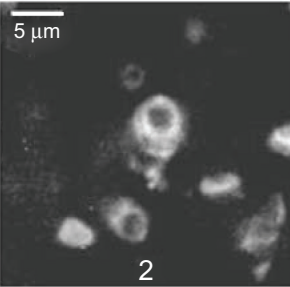

Onset

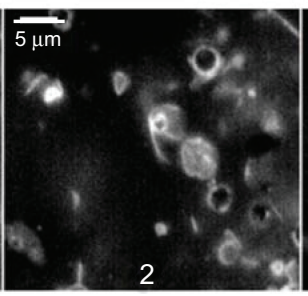

Onset

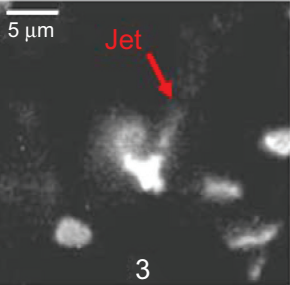

After

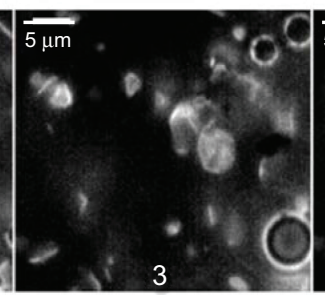

Opening

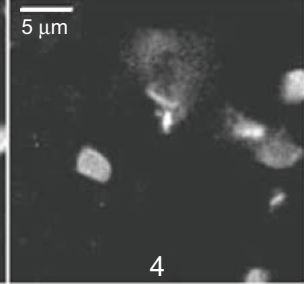

Diffusion of payload

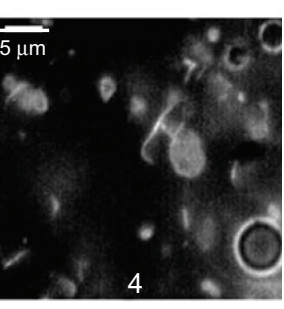

Opened

Figure 10 Rupture and payload release patterns of drug-delivery vehicles containing a microbubble. (A) The SHERPA drug-delivery particle contained a microbubble within a fluorescently labeled liposome and is indicated by the red circle. Upon ultrasound exposure, the microbubble underwent inertial cavitation and shattered the surrounding lipid membrane, creating a debris field of lipid particles and a jet. (B) At lower intensity, the ultrasound pulse caused the microbubble to undergo microstreaming instead of inertial cavitation, causing a single rupture in the surrounding lipid membrane with subsequent slow opening as a single piece.

Reprinted from Ibsen S, Benchimol M, Simberg D, Schutt C, Steiner J, Esener S. A novel nested liposome drug delivery vehicle capable of ultrasound triggered release of its payload. J Control Release. 20I I;I55(3):358-366, Copyright 20II, with permission from Elsevier. ${ }^{38}$

self-quenching dye has been loaded into the membrane of these microbubbles. In the compressed state, the membrane contracts and the dye molecules are in close proximity, causing quenching and reducing their fluorescent emission intensity, as shown in Figure 11. When in the expanded state, the membrane stretches and the dye molecules are separated from each other, decreasing the quenching effect, resulting in an increase in fluorescence intensity. The resulting fluorescence emission intensity modulation has a theoretical efficiency calculated to be $100 \% .{ }^{115}$ Fluorescence lifetime changes due to the modulated proximity of dyes on the microbubble would also be theoretically detectable. ${ }^{116}$ The expansion and contraction of the dye-loaded microbubble in response to focused ultrasound essentially makes the fluorescent microbubble "blink" at the driving frequency of the ultrasound..$^{57,114}$ Phase-sensitive detectors can be used to lock onto the frequency of this blinking signal that occurs only within the focal volume of the ultrasound. ${ }^{114}$ The ability to disregard the nonblinking background light from both the excitation light flooding the tissue and the surrounding fluorescent light from tissue outside the ultrasound focal volume allows the possibility to examine this blinking light inside the tumor to chemically interrogate just the focal volume of tissue. By incorporating fluorophores into the microbubble that are sensitive to their chemical environment and scanning an entire tissue region around a suspicious mass, biochemical information could be determined to enhance the accurate early detection of malignant cancer lesions.

\section{Challenges and limitations}

The drug payloads carried by any vehicle face the same challenge of unintentional accumulation within healthy tissue as Doxil ${ }^{\circledR}$. Although microbubbles are too large to extravasate into the creases of the hand, they will accumulate in the liver

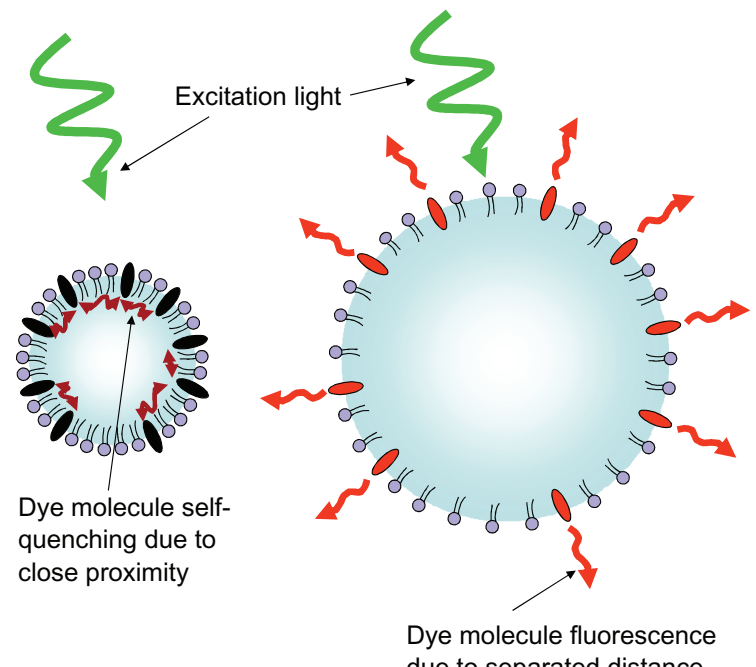

due to separated distance

Figure I I Schematic representation of the fluorescent light-modulating "blinking" microbubble contrast agent.

Notes: In the compressed state, shown on the left, the lipophilic dye molecules that have incorporated into the microbubble lipid monolayer shell are forced close together where they dissipate the absorbed excitation light through non-radiative self-quenching. In the expanded state, shown on the right, the dye molecules are separated from one another, reducing the self quenching effect and allowing the absorbed excitation light to be emitted as fluorescent light causing the microbubble to brighten. This increase and decrease in emitted light follows the frequency of the driving ultrasound pulse, allowing phase locking electronics to lock onto the blinking signal from the known location of the ultrasound focal zone. 
and spleen as these organs perform their natural clearance functions. As the vehicles degrade, the drug is released and can build up to toxic levels, despite the reduced exposure to other parts of the body such as the heart. One possible way to address this issue is to choose prodrug payloads. ${ }^{117}$ These are chemically modified versions of the active drug that display significantly reduced cytotoxicity. These prodrugs are triggered through various methods to a fully therapeutic form once inside the tumor tissue. The reduced toxicity of unactivated prodrug helps to reduce unintentional tissue toxicity in healthy tissue where the vehicles happen to accumulate.

An emerging interest has arisen with a phenomena observed in water suspensions of certain nanoparticles such as alumina. The nanoparticles themselves can serve as nucleation sites for inertial cavitation events to occur upon ultrasound exposure, ${ }^{118-120}$ which can lead to liposome lysis ${ }^{118}$ in a manner very similar to microbubble inertial cavitation. This means that nanoparticles could replace microbubbles as the trigger to activate drug-delivery vehicles. This is an exciting development because the drug-delivery vehicles could be made smaller than what microbubbles currently allow, opening the possibility for extravasation into the tumor which is not possible with the $1-2 \mu \mathrm{m}$ sized microbubbles. The nanoparticles can also potentially have much longer circulation half-lives. The $80-120 \mathrm{~nm}$ diameter Doxil ${ }^{\circledR}$ particles were shown to have a circulation half-life of 42 hours, ${ }^{11}$ whereas the $1-2 \mu \mathrm{m}$ microbubbles generally have a 3-15 minute half-life. ${ }^{121}$ The circulation time difference is also contributed to by the nanoparticles' lack of pressure sensitivity, allowing them to be better than microbubbles at surviving the pressure changes of traveling through the heart and lungs. Longer circulation times allow more of the particles to travel trough the tumor region, allowing for a higher achievable tumor delivery while reducing the amount that is taken up by the liver.

\section{Conclusion}

Microbubbles are unique from other traditional liposomebased drug-delivery vehicles because they have the ability to produce mechanical actuations and shockwaves when they interact with the focal zone of low intensity ultrasound. This creates a short distance mechanical force that is found nowhere else in the body outside of the ultrasound focal zone. This mechanical force is a starting point for many different designs of drug-delivery vehicles that use it to cause an immediate state change in the vehicle from its stable circulating form to an unstable drug-releasing form, creating burst releases of drug that are not achievable by traditional liposomes. The ultrasound can be used to highlight just the tumor tissue, creating a stark difference between the tissue inside and outside the focal zone. Ultrasound creates a level of contrast that is not achievable using triggers designed to destabilize liposomes that are based on biochemistry or environmental differences between the tumor and healthy tissue. This preferential and instantaneous opening of drugdelivery vehicles within the tumor tissue has the potential to reduce some of the dose-limiting side effects experienced by patients undergoing chemotherapy treatment. In addition to the drug-delivery capabilities, microbubbles can be used in cancer imaging and diagnostics. Microbubbles can generate contrast in ultrasound images, and ultrasound can also be used to generate cyclic expansion and contraction of microbubbles, producing new types of diagnostic contrast agents that are capable of producing light within the tumor itself.

These features make microbubbles a promising component in the effort to improve cancer treatment outcomes and reduce chemotherapy side effects.

\section{Disclosure}

Support was provided by Grant Numbers T32 CA121938 and R25 CA153915 from the National Cancer Institute. The content is solely the responsibility of the authors and does not necessarily represent the official views of the National Cancer Institute or the National Institutes of Health. The authors declare no conflicts of interest in this work.

\section{References}

1. Love RR, Leventhal H, Easterling DV, Nerenz DR. Side effects and emotional distress during cancer chemotherapy. Cancer. 1989;63(3) 604-612.

2. Monsueza J-J, Charniotb J-C, Vignatb N,Artigoub J-Y. Cardiac side-effects of cancer chemotherapy. Int J Cardiol. 2010;144(1):3-15.

3. Shapiro C, Recht A. Side effects of adjuvant treatment of breast cancer. N Engl J Med. 2001;344(26):1997-2008.

4. Nomura DK, Dix MM, Cravatt BF. Activity-based protein profiling for biochemical pathway discovery in cancer. Nat Rev Cancer. 2010;10(9):630-638.

5. Park J, Hong K, Kirpotin D, et al. Anti-HER2 immunoliposomes: enhanced efficacy attributable to targeted delivery. Clin Cancer Res. 2002;8:1172-1181.

6. Gottesman MM. Mechanisms of cancer drug resistance. Annu Rev Med. 2002;53:615-627.

7. Gabizon AA. Pegylated liposomal doxorubicin: metamorphosis of an old drug into a new form of chemotherapy. Cancer Invest. 2001;19(4) 424-436.

8. Miele E, Spinelli GP, Miele E, Tomao F, Tomao S. Albumin-bound formulation of paclitaxel (Abraxane ABI-007) in the treatment of breast cancer. Int J Nanomedicine. 2009;4:99-105.

9. Barenholz Y. Doxil ${ }^{\circledR}$ - the first FDA-approved nano-drug: lessons learned. J Control Release. 2012;160(2):117-134.

10. Cowens J, Creaven P, Greco W, et al. Initial clinical (Phase I) trial of TLC D-99 (doxorubicin encapsulated in liposomes). Cancer Res. 1993;53:2796-2802. 
11. Gabizon A, Catane R, Uziely B, et al. Prolonged circulation time and enhanced accumulation in malignant exudates of doxorubicin encapsulated in polyethylene-glycol coated liposomes. Cancer Res. 1994; 154:987-992.

12. Singal PK, Iliskovic N. Doxorubicin-induced cardiomyopathy. $N$ Engl J Med. 1998;339(13):900-905.

13. Olson RD, Mushlin PS. Doxorubicin cardiotoxicity: analysis of prevailing hypotheses. FASEB J. 1990;4(13):3076-3086.

14. Minotti G, Menna P, Salvatorelli E, Cairo G, Gianni L. Anthracyclines: molecular advances and pharmacologic developments in antitumor activity and cardiotoxicity. Pharmacol Rev. 2004;56:185-229.

15. Charrois GJ, Allen TM. Multiple injections of pegylated liposomal Doxorubicin: pharmacokinetics and therapeutic activity. J Pharmacol Exp Ther. 2003;306(3):1058-1067.

16. Gabizon A, Shmeeda H, Barenholz Y. Pharmacokinetics of pegylated liposomal Doxorubicin: review of animal and human studies. Clin Pharmacokinet. 2003;42(5):419-436.

17. Cheong I, Huang X, Bettegowda C, et al. A bacterial protein enhances the release and efficacy of liposomal cancer drugs. Science. 2006;314(5803):1308-1311.

18. Tietze LF, Neumann M, Möllers T, et al. Proton-mediated liberation of aldophosphamide from a nontoxic prodrug: a strategy for tumor-selective activation of cytocidal drugs. Cancer Res. 1989;49:4179-4184.

19. Brown JM, Wilson WR. Exploiting tumor hypoxia in cancer treatment. Nat Rev Cancer. 2004;4:437-447.

20. Breistøl K, Hendriks HR, Berger DP, Langdon SP, Fiebig HH, Fodstad $\mathrm{O}$. The antitumour activity of the prodrug N-L-leucyldoxorubicin and its parent compound doxorubicin in human tumour xenografts. Eur J Cancer. 1998;34(10):1602-1606.

21. Gopin A, Ebner S, Attali B, Shabat D. Enzymatic Activation of second-generation dendritic prodrugs: conjugation of self-immolative dendrimers with PEG via click chemistry. Bioconjug Chem. 2006;17: 1432-1440.

22. Shamis M, Lode HN, Shabat D. Bioactivation of self-immolative dendritic prodrugs by catalytic antibody 38C2. J Am Chem Soc. 2004;126:1726-1731.

23. Rooseboom M, Commandeur JN, Vermeulen NP. Enzyme-catalyzed activation of anticancer prodrugs. Pharmacol Rev. 2004;56(1): 53-102.

24. Allen TM. Ligand-targeted therapeutics in anticancer therapy. Nat Rev Cancer. 2002;2:750-763.

25. Karmali PP, Kotamraju VR, Kastantin M, et al. Targeting of albumin-embedded paclitaxel nanoparticles to tumors. Nanomedicine. 2009;5(1):73-82.

26. Murphy EA, Majeti BK, Barnes LA, et al. Nanoparticle-mediated drug delivery to tumor vasculature suppresses metastasis. Proc Natl Acad Sci U S A. 2008;105(27):9343-9348.

27. Sahoo SK, Labhasetwar V. Nanotech approaches to drug delivery and imaging. Drug Discov Today. 2003;8(24):1112-1120.

28. Moghimi SM, Hunter AC, Murray JC. Long-circulating and target-specific nanoparticles: theory to practice. Pharmacol Rev. 2001;53(2):283-318.

29. Allen T. Ligand-targeted therapeutics in anticancer therapy. Nat Rev Cancer. 2002;2:750-763.

30. Ulrich AS. Biophysical aspects of using liposomes as delivery vehicles. Biosci Rep. 2002;22(2):129-150.

31. Kolonin M, Pasqualini R, Arap W. Molecular addresses in blood vessels as targets for therapy. Curr Opin Chem Biol. 2001;5(3):308-313.

32. Hood JD, Bednarski M, Frausto R, et al. Tumor regression by targeted gene delivery to the neovasculature. Science. 2002;296(5577):2404-2407.

33. Beer AJ, Grosu AL, Carlsen J, et al. [18F]galacto-RGD positron emission tomography for imaging of alphavbeta3 expression on the neovasculature in patients with squamous cell carcinoma of the head and neck. Clin Cancer Res. 2007;13(22):6610-6616.

34. Su ZF, Liu G, Gupta S, Zhu Z, Rusckowski M, Hnatowich DJ. In vitro and in vivo evaluation of a Technetium-99m-labeled cyclic RGD peptide as a specific marker of alpha(V)beta(3) integrin for tumor imaging. Bioconjug Chem. 2002;13(3):561-570.
35. Vaupel P, Kallinowski F, Okunieff P. Blood flow, oxygen and nutrient supply, and metabolic microenvironment of human tumors: a review. Cancer Res. 1989;49:6449-6465.

36. Fradet Y, Islam N, Boucher L, Parent-Vaugeois C, Tardif M. Polymorphic expression of a human superficial bladder tumor antigen defined by mouse monoclonal antibodies. Proc Natl Acad Sci U S A. 1987;84:7227-7231.

37. Zanelli CI, DeMarta S, Hennige CW, Kadri MM. Beamforming for therapy with high intensity focused ultrasound (HIFU) using quantitative schlieren. In: Proceedings of the IEEE Ultrasonics Symposium; October 31-November 3, 1993; Baltimore, MD. 1993: 1233-1238.

38. Ibsen S, Benchimol M, Simberg D, Schutt C, Steiner J, Esener S. A novel nested liposome drug delivery vehicle capable of ultrasound triggered release of its payload. J Control Release. 2011;155(3):358-366.

39. Hindley J, Gedroyc WM, Regan L, et al. MRI guidance of focused ultrasound therapy of uterine fibroids: early results. Am J Roentgenol. 2004;183(6):1713-1719.

40. Kennedy JE, Ter Haar GR, Cranston D. High intensity focused ultrasound: surgery of the future? Br J Radiol. 2003;76(909):590-599.

41. Dromi S, Frenkel V, Luk A, et al. Pulsed-high intensity focused ultrasound and low temperature-sensitive liposomes for enhanced targeted drug delivery and antitumor effect. Clin Cancer Res. 2007;13: 2722-2727.

42. Wiart M, Curiel L, Gelet A, Lyonnet D, Chapelon J-Y, Rouvière $\mathrm{O}$. Influence of perfusion on high-intensity focused ultrasound prostate ablation: a first-pass MRI study. Magn Reson Med. 2007;58(1):119-127.

43. Xu LX, Zhu L, Holmes KR. Thermo regulation in the canine prostate during transurethral microwave hyperthermia, Part I: Temperature response. Int J Hyperthermia. 1998;14(1):29-37.

44. Nikfarjam M, Muralidharan V, Christophi C. Mechanisms of focal heat destruction of liver tumors. J Surg Res. 2005;127(2):208-223.

45. Coussios CC, Farny CH, Ter Haar G, Roy RA. Role of acoustic cavitation in the delivery and monitoring of cancer treatment by highintensity focused ultrasound (HIFU). Int J Hyperthermia. 2007;23(2): 105-120.

46. Khokhlova VA, Bailey MR, Reed JA, Cunitz BW, Kaczkowski PJ, Crum LA. Effects of nonlinear propagation, cavitation, and boiling in lesion formation by high intensity focused ultrasound in a gel phantom. J Acoust Soc Am. 2006;119:1834-1848.

47. Tachibana K, Feril LB, Ikeda-Dantsuji Y. Sonodynamic therapy. Ultrasonics. 2008;48(4):253-259.

48. Rosenthal I, Sostaric JZ, Riesz P. Sonodynamic therapy "a review of the synergistic effects of drugs and ultrasound." Ultrason Sonochem. 2004;11(6):349-363.

49. Stride E, Saffari N. Microbubble ultrasound contrast agents: a review. Proc Inst Mech Eng H. 2003;217:429-447.

50. de Jong N, Bouakaz A, Frinking P. Basic acoustic properties of microbubbles. Echocardiography. 2002;19(3):229-240.

51. Von Bibra H, Voigt JU, Froman M, Bone D, Wranne B, JuhlinDannfeldt A. Interaction of microbubbles with ultrasound. Echocardiography. 1999;16(7 Pt 2):733-741.

52. Schutt EG, Pelura TJ, Hopkins RM. Osmotically stabilized microbubble ultrasound contrast agents. Acad Radiol. 1996;3 Suppl 2:S188-S190.

53. Schutt E, Klein D, Mattrey R, Riess J. Injectable microbubbles as contrast agents for diagnostic ultrasound imaging: the key role of perfluorochemicals. Angew Chem Int Ed Engl. 2003;42:3218-3235.

54. Ferrara K, Pollard R, Borden M. Ultrasound microbubble contrast agents: fundamentals and application to gene and drug delivery. Annu Rev Biomed Eng. 2007;9:415-447.

55. Borden MA, Pu G, Runner GJ, Longo ML. Surface phase behavior and microstructure of lipid/PEG-emulsifier monolayer-coated microbubbles. Colloids Surf B Biointerfaces. 2004;35(3):209-223.

56. Kim DH, Costello MJ, Duncan PB, Needham D. Mechanical properties and microstructure of polycrystalline phospholipid monolayer shells: novel solid microparticles. Langmuir. 2003;19(20):8455-8466. 
57. Benchimol MJ, Hsu MJ, Schutt CE, Hall DJ, Mattreyc RF, Esener SC. Phospholipid/carbocyanine dye-shelled microbubbles as ultrasound-modulated fluorescent contrast agents. Soft Matter. Epub January 4, 2013.

58. Bloch SH, Wan M, Dayton PA, Ferrara KW. Optical observation of lipid-and polymer-shelled ultrasound microbubble contrast agents. Appl Phys Lett. 2004;84(4):631-633.

59. Chin CT, Lancée C, Borsboom J, et al. Brandaris 128: a digital 25 million frames per second camera with 128 highly sensitive frames. Rev Sci Instrum. 2003;74(12):5026-5034.

60. Chomas JE, Dayton P, May D, Ferrara K. Threshold of fragmentation for ultrasonic contrast agents. J Biomed Opt. 2001;6(2):141-150.

61. Postema M, van Wamel A, Folkert J, de Jong N. High-speed photography during ultrasound illustrates potential therapeutic applications of microbubbles. Med Phys. 2005;32:3707-3711.

62. Garbin V, Cojoc D, Ferrari E, et al. Changes in microbubble dynamics near a boundary revealed by combined optical micromanipulation and high-speed imaging. Appl Phys Lett. 2007;90:114103.

63. Dayton PA, Allen JS, Ferrara KW. The magnitude of radiation force on ultrasound contrast agents. J Acoust Soc Am. 2002;112(5): 2183-2192.

64. Bouakaz A, Versluis M, de Jong N. High-speed optical observations of contrast agent destruction. Ultrasound Med Biol. 2005;31(3): 391-399.

65. Dayton PA, Chomas JE, Lum AFH, et al. Optical and acoustical dynamics of microbubble contrast agents inside neutrophils. Biophys $J$. 2001;80:1547-1556

66. Chomas JE, Dayton P, May D, Ferrara K. Threshold of fragmentation for ultrasonic contrast agents. J Biomed Opt. 2001;6(2):141-150.

67. Crum LA. Surface oscillations and jet development in pulsating bubbles. J Phys (Paris). 1979;40(11):285-288.

68. Ferrara K, Pollard R, Borden M. Ultrasound microbubble contrast agents: fundamentals and application to gene and drug delivery. Annu Rev Biomed Eng. 2007;9:415-447.

69. Liu J, Lewis TN, Prausnitz MR. Non-invasive assessment and control of ultrasound-mediated membrane permeabilization. Pharm Res. 1998;15(6):918-924

70. Collis J, Manasseh R, Liovic P, et al. Cavitation microstreaming and stress fields created by microbubbles. Ultrasonics. 2010;50(2):273-279.

71. Kodama T, Tomita Y. Cavitation bubble behavior and bubble-shock wave interaction near a gelatin surface as a study of in vivo bubble dynamics. Appl Phys B. 2000;70:139-149.

72. Miller MW, Miller DL, Brayman AA. A review of in vitro bioeffects of inertial ultrasonic cavitation from a mechanistic perspective. Ultrasound Med Biol. 1996;22(9):1131-1154.

73. Ward M, Wu J, Chiu J-F. Experimental study of the effects of optison $^{\circledR}$ concentration on sonoporation in vitro. Ultrasound Med Biol. 2000;26(7):1169-1175.

74. Ward M, Wu J, Chiu JF. Ultrasound-induced cell lysis and sonoporation enhanced by contrast agents. J Acoust Soc Am. 1999;105(5): 2951-2957.

75. Karshafian R, Samac S, Banerjee M, Bevan P, Burns P. Ultrasound-induced uptake of different size markers in mammalian cells. Proceedings of the IEEE Ultrasonics Symposium; September 18-21, 2005:13-16.

76. Ross JP, Cai X, Chiu JF, Yang J, Wu J. Optical and atomic force microscopic studies on sonoporation. J Acoust Soc Am. 2002;111(3): 1161-1164.

77. Zhao YZ, Luo YK, Lu CT, et al. Phospholipids-based microbubbles sonoporation pore size and reseal of cell membrane cultured in vitro. J Drug Target. 2008;16(1):18-25.

78. Bao S, Thrall BD, Miller DL. Transfection of a reporter plasmid into cultured cells by sonoporation in vitro. Ultrasound Med Biol. 1997;23(6):953-959.

79. Koch S, Pohl P, Cobet U, Rainov NG. Ultrasound enhancement of liposome-mediated cell transfection is caused by cavitation effects. Ultrasound Med Biol. 2000;26(5):897-903.
80. Zarnitsyn V, Rostad CA, Prausnitz MR. Modeling transmembrane transport through cell membrane wounds created by acoustic cavitation. Biophys J. 2008;95(9):4124-4138.

81. Li ZG, Luo KQ, Ohl CD, Zhang JB, Liu AQ. A single-cell membrane dynamic from poration to restoration by bubble-induced jetting flow. Proceedings for the 15th International Conference on Miniaturized Systems for Chemistry and Life Sciences. 2011:94-96.

82. Okada K, Kudo N, Niwa K, Yamamoto K. A basic study on sonoporation with microbubbles exposed to pulsed ultrasound. J Med Ultrasonics. 2005;32:3-11.

83. Skyba DM, Price RJ, Linka AZ, Skalak TC, Kaul S. Direct in vivo visualization of intravascular destruction of microbubbles by ultrasound and its local effects on tissue. Circulation. 1998;98(4):290-293.

84. Lentacker I, De Geest BG, Vandenbroucke RE, et al. Ultrasound-responsive polymer-coated microbubbles that bind and protect DNA. Langmuir. 2006;22(17):7273-7278.

85. Felgner PL, Gadek TR, Holm M, et al. Lipofection: a highly efficient, lipid-mediated DNA-transfection procedure. Proc Natl Acad Sci USA 1987;84:7413-7417.

86. Cepko CL, Roberts BE, Mulligan RC. Constructions and applications of a highly transmissible murine retrovirus shuttle vector. Cell. 1984;37: 1053-1062.

87. Soughayer JS, Krasieva T, Jacobson SC, Ramsey JM, Tromberg BJ, Allbritton NL. Characterization of cellular optoporation with distance. Anal Chem. 2000;72:1342-1347.

88. Weaver JC, Chizmadzhev YA. Theory of electroporation: a review. Bioelectrochem Bioenerg. 1996;4:135-160.

89. Hapala I. Breaking the barrier: methods for reversible permeabilization of cellular membranes. Crit Rev Biotechnol. 1997;17(2):105-122.

90. Klibanov AL. Microbubble contrast agents targeted ultrasound imaging and ultrasound assisted drug-delivery applications. Invest Radiol. 2006;41(3):354-362.

91. Unger E, McCreery T, Sweitzer R, Caldwell V, Wu Y. Acoustically active lipospheres containing paclitaxel: a new therapeutic ultrasound contrast agent. Invest Radiol. 1998;33(12):886-892.

92. Liu Y, Miyoshi H, Nakamura M. Encapsulated ultrasound microbubbles: therapeutic application in drug/gene delivery. J Control Release. 2006;114:89-99.

93. Kheirolomoom A, Dayton PA, Lum AF, et al. Acoustically-active microbubbles conjugated to liposomes: characterization of a proposed drug delivery vehicle. $J$ Control Release. 2007;118:275-284.

94. Huang SL. Liposomes in ultrasonic drug and gene delivery. Adv Drug Deliv Rev. 2008;60:1167-1176.

95. Suzuki R, Takizawa T, Negishi Y, Utoguchi N, Maruyama K. Effective gene delivery with novel liposomal bubbles and ultrasonic destruction technology. Int J Pharm. 2008;354:49-55.

96. Suzuki R, Takizawa T, Negishi Y, et al. Tumor specific ultrasound enhanced gene transfer in vivo with novel liposomal bubbles. J Control Release. 2008;125:137-144.

97. Wrenn S, Dicker S, Small E, Mleczko M. Controlling cavitation for controlled release. Proceedings for the Ultrasonics Symposium (IUS) 2009 IEEE International. September 20-23, 2009:104-107. Rome.

98. Huang SL, MacDonald RC. Acoustically active liposomes for drug encapsulation and ultrasound-triggered release. Biochim Biophys Acta. 2004; 1665:134-141.

99. Goldberg BB, Liu JB, Forsberg F. Ultrasound contrast agents: a review. Ultrasound Med Biol. 1994;20(2):319-333.

100. Cosgrove D. Ultrasound contrast agents: an overview. Eur J Radiol. 2006;60(3):324-330.

101. Schmitz G. Ultrasonic imaging of molecular targets. Basic Res Cardiol. 2008;103(2):174-181.

102. Sanna V, Pintus G, Bandiera P, et al. Development of polymeric microbubbles targeted to prostate-specific membrane antigen as prototype of novel ultrasound contrast agents. Mol Pharm. 2011;8(3): 748-757.

103. Mauldin F, Dhanaliwala A, Patil A, Hossack J. Real-time targeted molecular imaging using singular value spectra properties to isolate the adherent microbubble signal. Phys Med Biol. 2012;57(16):5275-5293. 
104. Couture O, Dransart E, Dehay S, et al. Tumor delivery of ultrasound contrast agents using Shiga toxin B subunit. Mol Imaging. 2011;10(2): 135-143.

105. Anderson $\mathrm{CR}, \mathrm{Hu} \mathrm{X}$, Zhang $\mathrm{H}$, et al. Ultrasound molecular imaging of tumor angiogenesis with an integrin targeted microbubble contrast agent. Invest Radiol. 2011;46(4):215-224.

106. Kaufmann BA, Lindner JR. Molecular imaging with targeted contrast ultrasound. Curr Opin Biotechnol. 2007;18(1):11-16.

107. Xu RX, Huang J, Xu JS, et al. Fabrication of indocyanine green encapsulated biodegradable microbubbles for structural and functional imaging of cancer. J Biomed Opt. 2009;14(3):034020.

108. Rosenberg RD, Yankaskas BC, Abraham LA, et al. Performance benchmarks for screening mammography. Radiology. 2006;241(1): 55-66.

109. van Veen RL, Amelink A, Menke-Pluymers M, van der Pol C, Sterenborg HJ. Optical biopsy of breast tissue using differential path-length spectroscopy. Phys Med Biol. 2005;50(11):2573-2581.

110. Vaupel P, Schlenger K, Knoop C, Hockel M. Oxygenation of human tumors: evaluation of tissue oxygen distribution in breast cancers by computerized $\mathrm{O}_{2}$ tension measurements. Cancer Res. 1991;51(12): 3316-3322.

111. Janssen HL, Haustermans KM, Balm AJ, Begg AC. Hypoxia in head and neck cancer: how much, how important? Head Neck. 2005;27(7):622-638

112. Tromberg BJ, Shah N, Lanning R, et al. Noninvasive in vivo characterization of breast tumors using photon migration spectroscopy. Neoplasia. 2000;2(1):26-40.

113. Intes $\mathrm{X}$, Djeziri $\mathrm{S}$, Ichalalene $\mathrm{Z}$, et al. Time-domain optical mammography SoftScan: initial results. Acad Radiol. 2005;12(10): 1355 .
114. Schutt CE, Benchimol MJ, Hsu MJ, Esener SC. Ultrasound-modulated fluorescent contrast agent for optical imaging through turbid media. Proc SPIE. 2011; 8165: 81650B1-81650B7. Available at: http:// dx.doi.org/10.1117/12.894056.

115. Yuan B. Ultrasound-modulated fluorescence based on a fluorophore-quencher-labeled microbubble system. J Biomed Opt. 2009;14(2):240-243.

116. Yuan B. Sensitivity of fluorophore-quencher labeled microbubbles to externally applied static pressure. Med Phys. 2009;36(8): 3455-3469.

117. Ibsen S, Zahavy E, Wrasdilo W, Berns M, Chan M, Esener S. A novel Doxorubicin prodrug with controllable photolysis activation for cancer chemotherapy. Pharm Res. 2010;27(9):1848-1860.

118. Benchimol MJ, Ibsen SD, Simberg D, Wu Z, Mattrey RF, Esener SC. Quantified lysis of cell-like lipid membranes due to nanoparticle-facilitated cavitation. J Acoust Soc Am . 2011;130:2502.

119. Serpe L, Foglietta F, Canaparo R. Nanosonotechnology: the next challenge in cancer sonodynamic therapy. Nanotechnol Rev. 2012;1(2):173-182.

120. Tuziuti T, Yasui K, Sivakumar M, Iida Y, Miyoshi N. Correlation between acoustic cavitation noise and yield enhancement of sonochemical reaction by particle addition. J Phys Chem A. 2005; 109(21):4869-4872.

121. Willmann JK, Cheng Z, Davis C, et al. Targeted microbubbles for imaging tumor angiogenesis: assessment of whole-body biodistribution with dynamic micro-PET in mice. Radiology. 2008;249(1):212-219.
Drug Design, Development and Therapy

\section{Publish your work in this journal}

Drug Design, Development and Therapy is an international, peerreviewed open-access journal that spans the spectrum of drug design and development through to clinical applications. Clinical outcomes, patient safety, and programs for the development and effective, safe, and sustained use of medicines are a feature of the journal, which

\section{Dovepress}

has also been accepted for indexing on PubMed Central. The manuscript management system is completely online and includes a very quick and fair peer-review system, which is all easy to use. Visit http://www.dovepress.com/testimonials.php to read real quotes from published authors.

Submit your manuscript here: http://www.dovepress.com/drug-design-development-and-therapy-journal 